\title{
A PERSPECTIVA DAS PEDRAS: CONSIDERAÇÕES SOBRE OS NOVOS MATERIALISMOS E AS EPISTEMOLOGIAS ECOLÓGICAS
}

\author{
Isabel Cristina de Moura Carvalho ${ }^{1}$
}

Resumo: Este ensaio propõe a noção de epistemologias ecológicas e suas implicações para a pesquisa em educação ambiental. Estas epistemologias buscam demarcar a dimensão ecológica de uma virada ontológica na direção da simetria entre diferentes regimes de conhecimento e entre humanos e não humanos. Esse movimento pode ser identificado na obra de autores como Tim Ingold, Bruno Latour, Descola, De Landa, Deleuze e Guattari. Tendo esse debate ao fundo, o conceito proposto de epistemologias ecológicas apresenta-se como uma noção necessariamente plural. Não pretende designar uma unidade teórica, mas um movimento de abertura epistêmica inspirado na simetria, na materialidade e nos fluxos que tencionam a grande divisão sujeito e objeto, natureza e cultura. Tratase, nessa perspectiva epistemológica, de tomar o saber não como um conhecimento sobre o mundo, mas considerar regimes de conhecimento que se produzem com o mundo. Tal postura se contrapõe à via régia da ciência moderna, sustentada sobre a externalidade de um sujeito cognoscente humano fora do mundo, da natureza, e senhor de seus objetos de conhecimento.

Palavras-chave: Ontologia simétrica. Novos materialismos. Epistemologias ecológicas.

\section{THE PERSPECTIVE OF STONES: CONSIDERATIONS ON NEW MATERIALISMS AND ECOLOGICAL EPISTEMOLOGIES}

Abstract: This paper proposes the notion of ecological epistemologies and their implications for research in environmental education. These epistemologies seek to define the ecological dimension of an ontological turn in the direction of the symmetry between different regimes of knowledge and between humans and nonhumans. This movement can be identified in the work of authors such as Tim Ingold, Bruno Latour, Take Off, De Landa, Deleuze and Guattari. Having this debate in the background, the proposed concept of ecological epistemologies, presents itself as a notion necessarily plural. Not intended to designate a theoretical unity, but an opening toward the symmetry, the materiality and the streams that displace the great division between subject and object, and between nature and culture. It is pretty different to take the knowledge as something produced above the world, but consider that knowledge is produced with the world. This position contradicts the royal road of modern science, sustained on the externality of a knowing subject human out of the world of nature and Lord of their knowledge objects.

Keywords: Symmetric ontology. New materialism. Ecological epistemologies.

1 Doutora em Educação, Professora do Programa de Pós-Graduação em Educação da PUCRS, isabel.carvalho@gmail.com 


\section{LA PERSPECTIVA DE LAS PIEDRAS: CONSIDERACIONES SOBRE NUEVOS MATERIALISMOS Y LAS EPISTEMOLOGÍAS ECOLÓGICAS}

Resumen: En este trabajo se propone el concepto de epistemología ecológico y sus implicaciones para la investigación en educación ambiental. Estas epistemologías buscan demarcar la dimensión ecológica de un cambio ontológico en la dirección de la simetría entre los distintos regímenes de conocimiento entre los humanos y los no humanos. Este movimiento se puede identificar en la obra de autores como Tim Ingold, Bruno Latour, Descola, De Landa, Deleuze y Guattari. Teniendo este debate en el fondo, el concepto de las epistemologías ecológicas propuesto se presenta como un concepto necesariamente plural. Sin pretender designar a una unidad teórica, sino un movimiento de apertura epistémica inspirado en la simetría, en la materialidad y en los flujos que tienen la intención de fracturar las relaciones entre sujeto y objeto, naturaleza y cultura. Es, en esta perspectiva epistemológica, considerar el saber no como el conocimiento sobre el mundo, pero teniendo en cuenta los esquemas que producen conocimiento con el mundo. Esta actitud contrasta con las opciones de la ciencia moderna, sustentada en la exterioridad de un conocedor humano fuera del mundo de la naturaleza, y señor de sus objetos de conocimiento.

Palabras clave: Ontología simétrica. Nuevos materialismos. Epistemologías ecológicas.

\section{Introdução}

No mês de julho de 2013, nos reunimos no VII Encontro de Pesquisa em Educação Ambiental - EPEA, em Rio Claro, para a mesa A temática ambiental na pesquisa em educação ambiental: diferentes abordagens teórico-metodológicas materialismo histórico-dialético e epistemologias ecológicas. Naquela ocasião me coube uma fala de 20 minutos sobre epistemologias ecológicas. Era um tempo pequeno para expor um argumento que envolve vários pressupostos teóricos e o diálogo com os estudos sociais da ciência, os novos materialismos na filosofia, a antropologia ecológica de Tim Ingold. Mesmo assim, assumi o risco, sabendo que o que importa numa mesa redonda não é esgotar um assunto, mas compartilhar o pensar. Convidar outros para o diálogo quer concordem ou não com nossas proposições. Nesse sentido, pensar diz respeito à crítica, no sentido amplo da crítica, trazido por Foucault quando ele pergunta, é importante pensar?:

A crítica consiste em desentocar o pensamento e em ensaiar a mudança;
mostrar que as coisas não são tão evidentes quanto se crê, fazer de forma que
isso que se aceita como vigente em si não o seja mais em si. Fazer a crítica é
tornar difíceis os gestos fáceis demais. Nessas condições, a crítica - e a crítica
radical - é absolutamente indispensável para qualquer
transformação (FOUCAULT, 2006, p.180).

Agrego a esta citação uma imagem, a do belíssimo filme Hanna Arendt, cuja vida e obra podem ser situadas em torno da mesma questão: a convocação ao pensar, a dignidade de pensar mesmo quando isto custe muito, muito caro. 


\section{A noção de epistemologias ecológicas: uma breve demarcação}

Para abrir a exposição, iniciei minha fala com uma breve demarcação da noção de epistemologias ecológicas, tal como venho utilizando essa expressão. Importante destacar que se trata de um conceito em construção e não algo já consolidado. Nasce da necessidade de dar conta de indagações que têm se evidenciado ao estudar os modos de pensar as relações com o ambiente e os modos como o ambiente produz nossos modos de pensar. Como fazer ciência de um modo geral, e ciência da educação ambiental, em particular, desde uma perspectiva ambiental ou ecológica, que considere o ambiente como alteridade e existência livre da sua redução ao campo das representações humanas? São questões que parecem pertinentes para a educação ambiental, e têm norteado um importante debate epistemológico presente nas ciências humanas. Desde os limites de nossa pesquisa, temos buscado inserir a educação nesse diálogo. Por isso, essa noção está relacionada às leituras que temos feito, nos últimos anos, no âmbito do grupo de pesquisa SobreNaturezas ${ }^{2}$. Em nossos estudos temos nos deparado com questões tais como a crítica social da ciência normativa e o reconhecimento de uma pluralidade epistemológica que confere legitimidade a diferentes regimes de conhecimento do mundo. Ainda que Leff (2006) tenha optado pela expressão epistemologia ambiental para indicar, em direção semelhante a nossa, um ponto de inflexão produzido pela questão ambiental, neste momento, o adjetivo ecológico parece mais adequado, do nosso ponto de vista, na medida em que remete ao posicionamento de uma episteme inserida na trama das relações sociais e ambientais, humanas e não humanas, reciprocamente determinadas. Nesse sentido, entendemos as epistemologias ecológicas, como uma espécie de dobra ecológica - para usar um termo caro a Lacan da virada ontológica, que tem deixado ecoar a voz das coisas e o fluxo dos materiais no mundo, evitando recair nos conhecidos determinismos, sejam eles culturais ou biológicos. Para tornar compreensível esse argumento, temos trabalhado, até agora, com a expressão epistemologias ecológicas. Esta noção indica uma região do debate contemporâneo para onde convergem autores de múltiplas origens disciplinares, cujo área de interseção é a tentativa de superar as dualidades modernas -- tais como natureza e cultura, sujeito e sociedade, corpo e mente, artifício e natureza, sujeito e objeto -enfatizado aí continuidades e simetrias. A noção de epistemologias ecológicas não pretende designar, portanto, uma unidade teórica, mas pretende demarcar a convergência de certos modos de compreensão que recusam a externalidade do sujeito do conhecimento situado fora do mundo, da natureza e dos seus objetos de conhecimento.

\section{O debate e a pergunta que não quis calar}

Voltando ao auditório do EPEA. Apresentei algumas das ideias acima indicadas como bases para a compreensão do conceito de epistemologias ecológicas. Pois bem, o tempo de exposição é, sempre, inevitavelmente pequeno nessas ocasiões, e o debate também terminou ultrapassando o tempo preestabelecido. Assim, como é costume acontecer, questões ficam sem resposta, sobretudo na última rodada, quando já tínhamos vencido o tempo que nos era reservado. Por isso, pensei em elaborar esse

\footnotetext{
${ }^{2}$ Um grupo interdisciplinar formado por professores e orientandos do Programa de Educação da PUCRS e do Programa de Antropologia Social da UFRGS.
} 
texto, motivada pela questão a mim dirigida que deixei sem resposta naquela última rodada de perguntas.

Do fundo do auditório, uma moça pediu a palavra e perguntou algo mais ou menos assim: - Você disse que as epistemologias ecológicas pretendem considerar a perspectiva dos não humanos. Foi mencionada em sua fala a expressão a perspectiva da pedra. Você poderia me dizer qual é a perspectiva da pedra?

A pergunta era muito boa. O debate esquentou por outras razões e acabei não podendo retomar aquela pergunta. Mesmo não podendo responder, sai de lá com aquela indagação, simples e objetiva, na cabeça. Afinal, qual é a perspectiva da pedra? Como responder? Era uma pergunta que não poderia ser respondida como uma ou duas frases, daí a dificuldade de retomá-la, no final da manhã, quando tínhamos poucos minutos para um breve comentário a cada uma das muitas questões que se acumularam. Contudo, a pergunta permaneceu, insistente, ressoando como água em pedra dura, e aqui estou eu, afetada pela indagação e compelida a respondê-la.

A expressão perspectiva da pedra fora mencionada por mim, quando me referi a uma citação de Heidegger (2002), retomada por Tim Ingold (2011) quando este pontua a contraposição do humanismo heideggeriano em relação à ontologia simétrica, uma das bases das epistemologias ecológicas. A ontologia humanista clássica tem sido identificada reconhecidamente antropocêntrica, isto é, centrada no humano como fonte de todo pensamento válido no mundo inteligível. Os movimentos intelectuais contemporâneos que procuramos agrupar sob as epistemologias ecológicas têm em comum a intenção de operar um deslocamento dessa perspectiva humanista. Para estes trata-se não apenas de reconhecer a diversidade cultural e levar em conta o ponto de vista do outro humano, mas considerar o ponto de vista das coisas e dos organismos não humanos que habitam o mundo. O que está em questão, portanto, na distinção entre uma ontologia humanista e uma ontologia simétrica é a desconstrução do que Descola (2005) chama a grande divisão que institui a natureza e a cultura como dois reinos ontológicos antagônicos. Ao desfazer essa linha, encontramos, nos filósofos que se denominam novos materialistas (DE LANDA, 2003; ESCOBAR, 2007; BRYANT; SRNICEK; HARMAN, 2011), e também nos pensadores associados aos estudos sociais da ciência (Sciences Studies) como Bruno Latour, Donna Haraway (2003), Isabelle Stengers (2002) e, ainda, na antropologia ecológica de Tim Ingold, consequências de um pensamento que se situa para além da grande divisão. Ideias tais como coprodução, em Haraway (2003), ecologia da prática em Stengers (2005), engajamento entre humanos e não humanos, em Ingold (2000, 2011), enveredam por esse caminho. Essa posição se opõe à compreensão de Heidegger (1995, p. 263), quando este afirma que "a pedra é sem mundo, o animal é pobre em mundo e o ser humano é formulador de mundos". Em resposta à ontologia humanista Ingold (2011) afirma que a pedra possui um mundo. E, se a pedra possui um mundo, torna-se possível pensar em uma perspectiva da pedra.

Foi esse ponto, crucial para a compreensão do argumento das epistemologias ecológicas, que a jovem pesquisadora do fundo do auditório capturou em sua pergunta, me provocando a explicar o ponto de vista da pedra. Volto a dizer, a pergunta é ótima! Sobretudo porque há várias maneiras de responder. Vou contrastar, a seguir, dois caminhos de resposta, para efeito de esclarecer meu argumento e de atender à minha interlocutora, a quem devo este ensaio. 


\section{Os pontos de vista sobre o ponto de vista da pedra: possibilidades de resposta}

\subsection{A resposta do ventríloquo que fala pela pedra}

A primeira resposta é a resposta impossível. Aquela na qual eu diria: - a perspectiva da pedra é (...). Essa modalidade de resposta deve ser peremptoriamente evitada. No jogo retórico das perguntas e respostas, tal resposta seria imediatamente capturada pela armadilha que subjaz à pergunta. Não é possível responder pela pedra, falar em nome da pedra e se eu o fizesse estaria capitulando. Como nos jogos lógicos, eu estaria fora do jogo, não poderia mais continuar a rodada, nesse caso, o diálogo. Trata-se da resposta impossível, pois se eu a enunciasse estaria no lugar do ventríloquo, de quem fala pela pedra, e reincidiria na posição antropocêntrica, aquela em que o locutor humano se atribui o poder de falar pela natureza, ser o seu legítimo porta-voz. Aqui se desvela, justamente, a posição humanocentrada que as epistemologias ecológicas querem deslocar do horizonte epistêmico.

Falar pela pedra reincidiria numa posição já bastante desgastada, que é a do discurso biocêntrico. O argumento do biocentrismo, ao atribuir o status de sujeito à natureza, o fez tomando o modelo humano de sujeito. Portanto, apenas aparentemente contestou o antropocentrismo. Na verdade, apenas mudou o polo de atenção para a natureza, sem mudar a perspectiva centrada no humano. A projeção da condição subjetiva humana sobre a natureza ou sobre o planeta reitera uma espécie de animismo ecológico, que em nada se afasta do antropocentrismo. Apenas, num ato de desejo, tenta humanizar a natureza, sem mudar o dualismo e o antagonismo sociedade e natureza, humanos e não humanos.

\subsection{A resposta argumentativa: o reconhecimento da vida das coisas}

A compreensão de que a pedra tem mundo atribui a ela o que esteve restrito à condição humana ao plano das coisas. Essa é uma operação de grande ousadia em nossa tradição humanista, e que demandaria muito mais do que este breve ensaio para ser discutida em todas as suas consequências. Importa, aqui, entretanto, fixar um ponto de inflexão do novo materialismo. Nessa perspectiva, não se trata de falar pela pedra ou adivinhar seus desejos, humanizando-a. Nem de explicá-la desde as ciências naturais. Trata-se de saber, no sentido da educação da atenção (INGOLD, 2010) a vida da pedra e deixar-se afetar por ela. Perceber o pulsar do mundo onde vivemos e com o qual interagimos constantemente, ainda que essa vida seja constantemente apagada e silenciada em nossa cultura humanocentrada. Apenas para ficar na perspectiva da pedra, que é um bom mote para esta discussão, passo ao primeiro de três exemplos que, a partir daqui, trago para os leitores deste artigo.

\subsubsection{As pedras e os vinhos}

Em 2012, na cidade de Mendonza, Argentina, pude visitar uma importante vinícola, com suas caves feitas de pedra para melhor maturar os vinhos ali produzidos. Ao visitar essa área da produção de vinhos, o enólogo que nos guiava dizia como cada garrafa ali armazenada sofria os efeitos daquele ambiente. A temperatura, a umidade, a luz estavam relacionadas aos modos particulares daquela ambiência trabalhar o vinho. Ou seja, envolverem as garrafas num microclima bastante específico. Desde o plantio das uvas, as condições do solo, do clima, os processos de transformação da uva até os 
tempos de espera em grandes recipientes de madeira ou metal, o engarrafamento e depois o tempo de espera do vinho já engarrafado na adega. Nessa etapa final, o contato com as pedras, a localização das garrafas dentro da adega, a ação do tempo, e os tipos de vinho ali armazenados convivem de modo a produzir sabores e aromas próprios, singulares e sazonais, para cada uma daquelas variedades de vinho em ativo processo de maturação. Esse convívio do vinho com a adega de pedra gera resultados não totalmente previsíveis e produz diferenças de safra a safra. Assim, no mundo dos vinhos, se tivermos a atenção educada para tanto, pode-se desfrutar dos saberes e da arte da apreciação dos vinhos. Um apreciador de vinhos saberá identificar que o mesmo vinho de uma determinada safra é mais ácido ou mais redondo, possui toques mais acentuados de chocolate ou de pimenta, diferenciando-o do mesmo vinho, porém de outra safra. $\mathrm{O}$ vinho adquire personalidade. E, como sabemos, as características de safra influem no valor do vinho, o constituem, propriamente. Essa situação, por exemplo, nos mostra como o mundo das pedras é eloquente e ativo na coprodução de um dos mais famosos vinhos de Mendoza. Eis aqui a vida das pedras na cadeia produtiva, social e ambiental, humana e não humana, do prestigiado vinho com certificação de origem, um dos patrimônios materiais e imateriais dos nossos vizinhos argentinos. Nos termos de Bruno Latour $(2002,2004)$, que pensa a conexão humanos e não humanos nos termos de rede sociotécnica, diríamos que as pedras são agentes ou atores na rede sociotécnica da produção vinícola. Nos termos de Ingold (2011), que pensa em termos de malha (meschwork) as pedras são matéria viva em movimento, conferindo qualidades ao vinho, outra matéria viva, ambas em uma mesma malha entretecida, da qual também, ao nosso modo, participamos.

\subsubsection{O artista, o violão e a ambiência da criação}

Saindo do mundo dos vinhos para o mundo da música, mas continuando no Sul - agora o Sul do Brasil - penso no musico gaúcho Victor Ramil. Esse cantor e compositor lançou, em 2013, um CD intitulado: Foi no mês que vem. Trabalho no qual o artista canta suas composições, acompanhado apenas de seu violão. Victor Ramil deu várias entrevistas na mídia por ocasião do lançamento. Numa delas, para a Rádio Band News, ele disse que já não poderia compor nem cantar suas canções sem se pensar colado ao violão, como uma extensão de seu corpo. Em outro depoimento, para o Jornal Zero Hora, ele mostra o ambiente em que compõe, a sua casa na cidade de Pelotas, no Sul do Rio Grande do Sul. Uma casa de tipo colonial, com móveis de madeira, chão de tábuas corridas, pé direito alto. A entrevista é gravada numa peça da casa onde ele tem sua estação de trabalho, com muitos quadros na parede e janelas voltadas para a rua. Ali ele relata como durante o trabalho ouve seu cachorro, observa o movimento da rua, se concentra e se distrai quando está compondo suas músicas e escrevendo seus romances, considerando esse ambiente (essa atmosfera) como parte de sua criação.

O depoimento dessa experiência criativa do compositor Victor Ramil contribui para pensarmos o engajamento no contínuo humano e não humano como fluxo produtivo na obra do artista. Nesse sentido, o violão, a casa, o quarto, a rua, o cachorro e as pessoas que passam lá fora fazem parte da malha de relações à qual o artista pertence e com a qual produz. O contínuo humano e não humano é condição para a produção artística do músico. Em termos da virada ontológica a questão já não seria: quem é o autor da música, o violão ou o compositor? A casa ou a mente que a habita? A melhor resposta, desde o que chamamos aqui, metaforicamente, de a perspectiva das 
pedras seria a de que o autor da obra não é um nem outro, mas o fluxo generativo dessas relações de mútua afecção.

\subsubsection{O mundo intelectual e a produção cientifica: há vida possível}

Finalmente, chego ao mundo da criação intelectual e acadêmica. E insisto em crer, talvez ingenuamente, que existem espaços de autêntica criação intelectual em nosso ambiente acadêmico. Os menos crédulos diriam que esses espaços de criação existem apesar do ambiente acadêmico. São os lugares de pensamento como chamaria Hanna Arendt, lugares de não ceder ao argumento simples, fácil e repetitivo que tem audiência certa. Espaços de resistência ao insulamento burocrático (NUNES, 1996), a uma racionalidade instrumental e empobrecedora como já foi apontado por vários de nossos colegas (NETTO MACHADO; BIANCHETTI, 2011; TREIN; RODRIGUES, 2011; SPINK; ALVES, 2011; MISOCZKY; GOULART, 2011; CABRAL; LAZZARINI, 2011.). Concordo com essas análises e sofro, como tantos, as agruras desse espírito calculista do nosso tempo. Contudo, não se trata de objetivar a academia como se ela existisse fora de nós, alienando-nos e nos tornando vítimas, quando somos coparticipes. Assim, apesar do Hommo Lattes (MARTINS, 2013), penso que é quando não cedemos de nosso desejo de pensar que produzimos o tempo-espaço extraordinário do pensamento. Aquele que Arendt contrapõe à banalização do mal e ao modelo do funcionário exemplar, tão bem encarnado por Eicheman.

Após essa digressão, passo, então, ao último exemplo, do livro de Tim Ingold (2011). Ingold é professor, pesquisador e foi diretor do departamento de antropologia na Aberdeem University por vários anos. Em um ambiente acadêmico de crise das ciências humanas na Europa e, segundo ele mesmo, de pouca recepção para a reflexão antropológica, o prof. Ingold segue levando a cabo um pensamento instigante e produtivo que tira da zona de conforto os cânones da ciência normal. Em seu livro Being Alive, de 2011, estabelece um diálogo com os novos materialismos, com a obra filosófica de Deleuze e Guattari, com a fenomenologia, e segue na perspectiva de uma ontologia simétrica. Uma postura que aproxima os seres humanos não apenas dos animais, mas também das pedras, dos mares, dos céus, dos ventos, da rugosidade dos solos, dos movimentos das marés. Todos aqueles que partilham da mesma atmosfera ou que habitam o mesmo mundo-ambiente são transpassados e constituídos pela vida, que não é ser silenciado na produção de nossas ideias e teorias. Nesse sentido, é com certa perplexidade que ele critica o apagamento, em nossa produção científica, dos fluxos da vida das coisas, dos materiais e dos não humanos que tornam possível nossa atividade intelectual. Assim, damos crédito e registramos em nossas referências os textos e os autores que lemos e nos esquecemos da influência decisiva das condições vitais que possibilitaram a nossa produção, como se vivêssemos apenas no mundo das abstrações. Os textos acadêmicos muito raramente citam as condições em que foram produzidos. Raramente as companhias humanas e não humanas que partilharam a escrita de um livro, as experiências auditivas, táteis, visuais que inspiraram ideias e insights são creditadas na produção. Na tentativa de quitar essa dívida, Ingold usa o prólogo de Being alive para descrever, exaustiva e detalhadamente, a atmosfera e o ambiente que propiciaram a escrita do livro. Estão lá, referenciadas, a aconchegante casa do lago Pielinen na Finlândia, a paisagem de verão na Europa do Norte, a presença de sua esposa Ana de sua filha mais nova, Suzana, os rumores e silêncios do ambiente, o gato da casa, seus humores, bem como as condições institucionais que lhe permitiram retirar- 
se da universidade por um semestre sabático, para reunir e escolher, dentre os ensaios produzidos nos últimos dez anos, aqueles que comporiam seu livro mais recente. Enfim, ele dá crédito às condições que, mais do que permitiram produzir o livro, foram coautoras de Being Alive ${ }^{3}$.

\section{Ao final: de volta à pedra}

O deslocamento epistemológico que procurei delinear neste artigo diz respeito a tomar o conhecimento do mundo não como um saber sobre o mundo e os seres que o habitam, mas considerar regimes de conhecimento que se produzem com e no mundo. $\mathrm{O}$ engajamento, ou o estar no mundo no sentido experiencial, é condição para conhecê-lo. A compreensão ou o conhecimento, nesse sentido, é também o reconhecimento daquilo que torna possível aos organismos humanos e não humanos existirem, conviverem e constituírem a si mesmos e ao mundo em contínua relação.

A centralidade atribuída à vida e aos materiais, nessa perspectiva, reitera a preocupação fenomenológica com a qual vimos trabalhando desde pesquisas anteriores, e a amplia, agora com acréscimos e desdobramentos mais radicais. Para o educador e o pesquisador ambiental essa postura epistemológica desafia a acompanhar os materiais e descrever suas propriedades, estar atento às inflexões aos diferentes arranjos, disposições e afecções particulares das coisas, corpos, pessoas e ambiente. Trata-se de deixar o modelo hilemórfico, onde a vida se constitui desde a relação de determinação entre matéria e forma, substância e atributos. Em contraposição a esse ideal, que remonta à filosofia da matéria em Aristóteles, Ingold (2011) traz da obra "Mil Platôs" de Deleuze e Guattari, publicada em 1995, a proposição generativa de que a vida não está na fixidez da associação forma e substância, mas na permanente transformação de materiais e forças que se entretecem no contínuo da vida. O modelo hilemórfico instituiu no pensamento moderno a noção de objeto como continente estável da captura e contenção de um processo de forças. O objeto é a cristalização dos fluxos. Para Ingold, que, nesse ponto segue Heidegger, o objeto é o contrário da coisa. A coisa está relacionada aos fluxos e aos materiais: "É no contrário da captura e da contenção - na descarga e no vazamento - que descobrimos a vida das coisas. Com isso em mente podemos voltar a Deleuze e Guattari chamam de matéria-fluxo e eu chamaria de material" (INGOLD, 2012, p. 35).

Desse mesmo ponto de vista, viver no mundo não é ocupar um lugar em meio a um ambiente povoado de objetos, mas ao contrário, é juntar-se ao processo de formação e permanente transformação das coisas vivas, humanas e não humanas. Coisas como árvores, pedras e nuvens são evocadas por Ingold (2011) para mostrar como é relativo tentar demarcar fronteiras de onde começa e termina a vida das coisas. Há muitas vidas e processos generativos, por exemplo, numa árvore: vidas de insetos, vegetais, pequenos animais, ação do vento, do clima, do dia, da noite, das aves entre outras formas de vida vivendo e produzindo vida $\mathrm{ali}^{4}$. Finalizo com as palavras de Ingold (2011, p.31): “os

\footnotetext{
${ }^{3}$ Esse prólogo e outras contribuições de Being Alive é objeto de discussão no livro que resultou do seminário com Tim Ingold no Brasil, em 2011 (STEIL; CARVALHO, 2012a e 2012b).

${ }^{4}$ Ainda nessa direção, destaco uma instigante conferência, em 2012, do pesquisador em imunologia da PUCRS, Prof. Moisés Bauer. Ele argumentou sobre as mudanças de perspectiva na imunologia desde que esta ultrapassou um conceito de organismo humano como unidade biológica autônoma para compreendêlo como um nicho de vidas e seres que o constituem. As decorrências desse organismo, compreendido como um parlamento de outras vidas e não como uma totalidade orgânica fechada, muda a compreensão da imunologia baseada na polarização entre ameaças externas e reações internas do corpo humano.
} 
humanos figuram no contexto das pedras, assim como as pedras figuram no contexto dos humanos". Tais contextos, para Ingold, são como regiões de um mesmo território. As pedras têm mundo, as pedras têm história. As pedras são forjadas pelas linhas que se entrelaçam nelas e as entrelaçam com as linhas de outros organismos, que podem incluir ou não os seres humanos.

Espero ter respondido à pergunta da jovem do auditório. Espero, talvez, ter deixado outras perguntas.

\section{Referências}

BRYANT, L. SRNICEK, N.; HARMAN, G. (Eds.). "The speculative turn: continental materialism and realism”. Open Source. 2011 [re-press]. Disponível em: http://www.repress.org/book- files/OA_Version_Speculative_Turn_9780980668346.pdf. Acesso em: 03 mai. 2014.

CABRAL, S.; LAZZARINI, S.G. Internacionalizar é preciso, produzir por produzir não é preciso. Organ. Soc. [online], Salvador, v.18, n.58, p. 541-542, jul/set, 2011. Disponível em: $<$ http://www.scielo.br/scielo.php?pid=S1984-92302011000300011\&script=sci_arttext $>$. Acesso em: 02 abr. 2014.

CARVALHO, I.C.M.; STEIL, C.A. Percepção e ambiente: aportes para uma epistemologia ecológica. Rev. Eletrônica Mestr. Educ. Ambient., Porto Alegre, V. especial, p.59-79, mar. 2013. Disponível em: <http://www.seer.furg.br/remea/article/view/3443/2069>. Acesso em: 15 abr. 2014.

DE LANDA, M.. A new ontology for the social sciences. New ontologies: transdisciplinary objects. March 2. 2003a.

DELEUZE, G.; GUATTARI, F. Mil platôs. vs. 1 a 5. Rio de Janeiro: Editora 34, 1995.

DESCOLA, P. Par-delà nature et culture. Paris: Éditions Gallimard, 2005.

ESCOBAR, A. The 'ontological turn' in social theory. A Commentary on 'Human geography without scale', by Sallie Marston, John Paul Jones II and Keith Woodward. Transactions of the Institute of British Geographers, London, v.32, n.1, p.106-111, Jan. 2007.

FOUCAULT, M. Est-il donc important de penser? In: FOUCAULT, M. Dits et écrits IV (19801988). Paris: Gallimard, 2006. p. 178-182.

HARAWAY, D. J. The companion species manifesto: dogs, people, and significant otherness. Chicago: Prikly Paradigm Press, 2003.

HEIDEGGER, M. Construir, habitar, pensar. In: HEIDGGER, M. Ensaios e conferências. Petrópolis: Vozes, 2002. p.25-141

HEIDEGGER, M. The fundamental concepts of metaphysics: word, finitude, solitude. Bloomington: Indiana University Press, 1995.

INGOLD, T.Trazendo as coisas de volta à vida: emaranhados criativos num mundo de materiais. Horizontes Antropológicos, Porto Alegre, v. 18, n.37, p.25-44, jan./jun. 2012. 
Disponível em: < http://www.scielo.br/scielo.php?pid=S0104-

$71832012000100002 \&$ script=sci_arttext $>$. Acesso em: 15 abr. 2014.

INGOLD, T. Being Alive: essays on movement, knowledge and description. Londres/Nova York: Routledge, 2011.

INGOLD, T. Da transmissão de representações à educação da atenção. Educação, Porto Alegre, v. 33, n. 1, p. 6-25, jan./abr, 2010.

INGOLD, T. The perception of the environment; essays in livelihood, dwelling and skill. London/New York: Routledge, 2000.

LATOUR, B. Politics of nature: how to bring the sciences into democracy. Cambridge: Harvard University Press, 2004.

LATOUR, B. What is Given in Experience? A Review of Isabelle Stengers Penser avec Whitehead : Une libre et sauvage création de concepts. Paris: Gallimard, 2002.

LEFF, E. Aventuras de la epistemologia ambiental; de la articulación de las ciencias al diálogo de saberes. México, D F. Siglo XXI, 2006.

MARTINS, S.B. Hommo Lattes. In: $O$ Globo [Blogs online]. Disponível em: <http://oglobo.globo.com/blogs/prosa/posts/2013/08/02/homo-lattes-505601.asp>. Acesso em: 27 ago. 2013.

MISOCZKY, M.C.; GOULART, S. Viver as contradições e tornar-se sujeito na produção social de nosso espaço de práticas. Organ. Soc., Salvador, v.18, n.58, p.535-540, jul./set. 2011.

Disponível em: <http://www.scielo.br/scielo.php?pid=S1984-

92302011000300010\&script=sci_arttext>. Acesso em: 15 abr. 2014.

NETTO MACHADO, A.M.; BIANCHETTI, L. (Des)fetichização do produtivismo acadêmico: desafios para o trabalhador-pesquisador. RAE - Revista de Administração de Empresas, São Paulo, v.51, n.3, p.244-254, mai./jun. 2011. Disponível em:

<http://rae.fgv.br/sites/rae.fgv.br/files/artigos/10.1590_S0034-75902011000300004.pdf>. Acesso em: 15 abr. 2014.

NUNES, E. A gramática política do Brasil: clientelismo e insulamento burocrático. Rio de janeiro: Jorge Zahar, 1996.

SPINK, P.K.; ALVES, M.A. O campo turbulento da produção acadêmica e a importância da rebeldia competente. Organização \& Sociedade, Salvador, v. 18, n. 57, p. 337-343, abr./jun. 2011. Disponível em: <http://www.revistaoes.ufba.br>. Acesso em: 27 Ago.2013.

STEIL, C.A.; CARVALHO, I.C de M. "Apresentação". In: (Orgs.), Cultura, percepção e ambiente. Diálogos com Tim Ingold. São Paulo: Editora Terceiro Nome, 2012a.

STEIL, C.A.; CARVALHO, I.C de M. Diferentes aportes no âmbito da antropologia fenomenológica. In: . (Orgs.), Cultura, percepção e ambiente. Diálogos com Tim Ingold, São Paulo, Editora Terceiro Nome, 2012b. p. 31-47.

STENGERS, I. Penser avec Whitehead: une libre et sauvage création de concepts. Paris: Seuil, 2002. 
Pesquisa em Educação Ambiental, vol. 9, n. 1 - págs. 69-79, 2014

STENGERS, I. Introductory notes on an ecology of practices. Cultural Studies Review, Melbourne, v.11 n.1, p.183-196, Mar. 2005.

TREIN, E.; RODRIGUES, J. O canto de sereia do produtivismo científico: o malestar na Academia e o fetichismo do conhecimento-mercadoria. Universidade \& Sociedade, Brasília, v.20, n.47, p.122-132, fev. 2011.

Artigo submetido em 19/12/2013

Artigo aprovado em 09/03/2014 